\title{
Micro-Fluidic Dye Ring Laser - Experimental Tuning of the Wavelength and Numerical Simulation of the Cavity Modes
}

\author{
Gersborg-Hansen, Morten; Balslev, Søren; Mortensen, Niels Asger; Kristensen, Anders
}

Published in:

2006 Quantum Electronics Lasers and Electro-Optics

Link to article, DOI:

10.1109/CLEO.2006.4627734

Publication date:

2006

Document Version

Publisher's PDF, also known as Version of record

Link back to DTU Orbit

Citation (APA):

Gersborg-Hansen, M., Balslev, S., Mortensen, N. A., \& Kristensen, A. (2006). Micro-Fluidic Dye Ring Laser Experimental Tuning of the Wavelength and Numerical Simulation of the Cavity Modes. In 2006 Quantum Electronics Lasers and Electro-Optics (pp. 1-2). IEEE. https://doi.org/10.1109/CLEO.2006.4627734

\section{General rights}

Copyright and moral rights for the publications made accessible in the public portal are retained by the authors and/or other copyright owners and it is a condition of accessing publications that users recognise and abide by the legal requirements associated with these rights.

- Users may download and print one copy of any publication from the public portal for the purpose of private study or research.

- You may not further distribute the material or use it for any profit-making activity or commercial gain

- You may freely distribute the URL identifying the publication in the public portal 


\title{
Micro-Fluidic Dye Ring Laser - Experimental Tuning of the Wavelength and Numerical Simulation of the Cavity Modes
}

\author{
Morten Gersborg-Hansen, Søren Balslev, Niels Asger Mortensen, and Anders Kristensen \\ MIC - Department of Micro and Nanotechnology, Nano DTU, Technical University of Denmark (DTU), \\ Building 345east, Ørsteds Plads, DK-2800 Kongens Lyngby, Denmark. \\ www.mic.dtu.dk/nil \\ mgh@mic.dtu.dk
}

\begin{abstract}
We demonstrate wavelength tuning of a micro-fluidic dye ring laser. Wavelength tunability is obtained by controlling the liquid dye concentration. The device performance is modelled by FEM simulations supporting a ray-tracing view.

(C)2006 Optical Society of America

OCIS codes: (140.2050) Dye Lasers; (140.3410) Laser Resonators
\end{abstract}

\section{Introduction}

Integration of light sources onto lab-on-a-chip micro-systems are of great interest for future lab-on-a-chip applications [1]. For applications where tunable light in the visible range is preferable, e.g. for on-chip spectral analysis of chemical samples, dye lasers are of particular interest. Recently, there has been an increasing effort in realizing micro-fluidic dye lasers by glass [2] or polymer microfabrication $[3,4]$.

Here, as in [2-4], a planar ring cavity consisting of two isosceles dielectric triangles and a micro-fluidic channel is considered. Fig. 1(a) shows a microscope image of the fabricated polymer device.

The micro-fluidic dye ring laser was first demonstrated in [3]. Here, we demonstrate tunability of the laser wavelength by varying the dye concentration (Rhodamine 6G dissolved in ethanol), and the device is modelled by finite-element simulations.

In the simulations, we study the full-wave nature of the TE cavity modes in the 2D geometry shown in Fig. 2(a) using the finite-element method (FEM) and compare the results to a plane-wave model. In the plane-wave view often used to explain the function of the laser [2-4], the cavity relies on total internal reflection of plane-waves at the interfaces between the glass/polymer triangles and the surrounding air at an incidence angle of $45^{\circ}$. Our simulation supports this picture and we explain the cavity modes as standing waves in the cavity.

\section{Experimental concentration tuning of the laser wavelength}

By varying the dye concentration in the micro-fluidic channel, see Fig. 1(a), we demonstrate tuning of the over-all laser wavelength from $565 \mathrm{~nm}-569 \mathrm{~nm}$, see Fig. 1. The laser is pumped by a frequency doubled Nd:YAG laser at $532 \mathrm{~nm}$ ( $5 \mathrm{~ns}$ pulse length, $10 \mathrm{~Hz}$ repetition rate). For details on the fabrication and characterization of the laser, we refer to [3].

This tuning effect was investigated for Rhodamine 6G solutions by Peterson et al. in 1971 [6] and can be used for real-time tuning of the laser wavelength by integration of a micro-fluidic mixer on the chip [4,7].

(a)

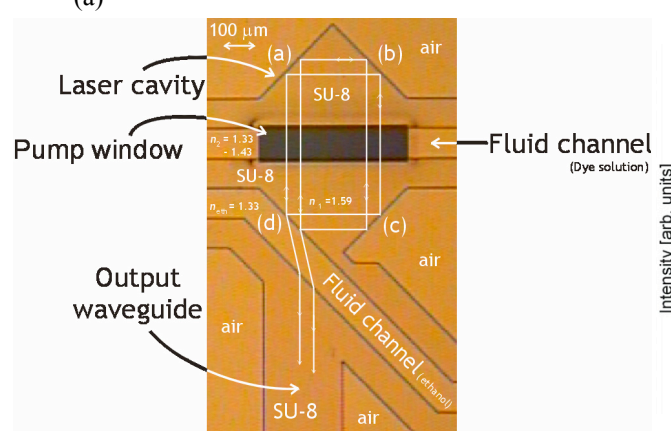

(b)

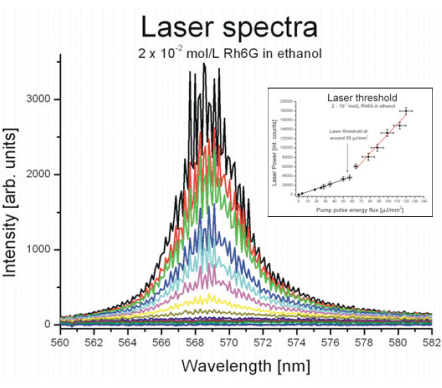

(c)

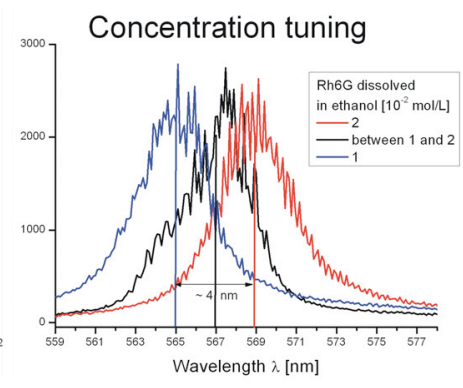

Fig. 1 (a) Microscope image of the fabricated polymer device (SU-8 polymer). The triangles have a base-line of $500 \mu \mathrm{m}$. (b) Laser output spectra with Rhodamine 6G dissolved in ethanol in the micro-fluidic channel as the active medium.

(c) Tuning of the laser wavelength between $565-569 \mathrm{~nm}$ by varying the dye concentration. 


\section{CMFF5.pdf}

\section{Numerical simulation}

In order to gain further understanding of the laser resonator, we have modelled the electric field in the cavity by FEM simulations. The electric field in the cavity is governed by the wave equation $\nabla \times \nabla \times \mathbf{E}(\mathbf{r})=n^{2}(\mathbf{r}) k^{2} \mathbf{E}(\mathbf{r})$ where $\mathbf{E}$ is the electric field, $n$ is the refractive index, and $k=\omega / c$ is the wavenumber.

We have solved the wave equation in the frequency domain for TE modes in the planar geometry shown in Fig. 2(a), i.e. $\mathbf{E}(\mathbf{r})=E_{z}(\mathbf{r}) \mathbf{e}_{z}$ and $\mathbf{r}=x \mathbf{e}_{x}+y \mathbf{e}_{y}$, by applying a FEM technique. A point-source has been inserted in the cavity at point A, see Fig. 2(a), to excite the electric field in the cavity. The light in the cavity is coupled to the adjacent polymer region (waveguide) by evanescent-field coupling. The output power $P_{\text {out }}$ at a certain excitation wavelength ( $k$ value) is calculated by integration of the time-averaged power through the line $\gamma$, see Fig. 2(a). We refer to [5] for details.

A simple plane-wave ray-tracing argument predicts cavity resonances for integer values of the mode index $m$, defined as $m(k)=k L_{\mathrm{rt}} / 2 \pi+\phi / 2 \pi$ [5] where $L_{\mathrm{rt}}$ is the round-trip optical path length, i.e. $L_{\mathrm{rt}}=2 n_{1} \ell_{1}+2 n_{2} \ell_{2}$, and $\phi$ is the phase picked up by a plane wave at total internal reflection at the polymer/air interface at an incidence angle of $45^{\circ}$.

The results show excellent agreement with the plane-wave prediction from $m \sim 10$ and up, see Fig. 2, thus our simulations support a ray-tracing view of the cavity resonances. Unlike for dispersion-guided resonances in a square 2D photonic-crystal [8], we are able to explain the spectrum in terms of standing waves with a mode spacing of $\delta k=2 \pi / L_{\mathrm{rt}}$.

(a)

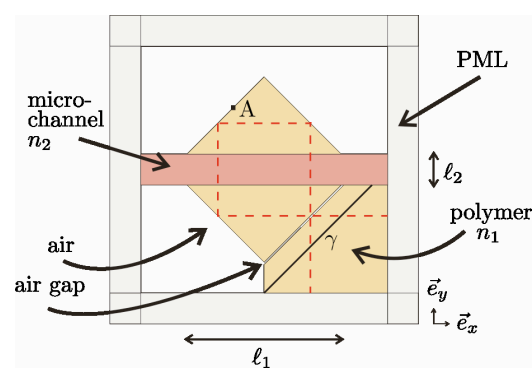

(b)

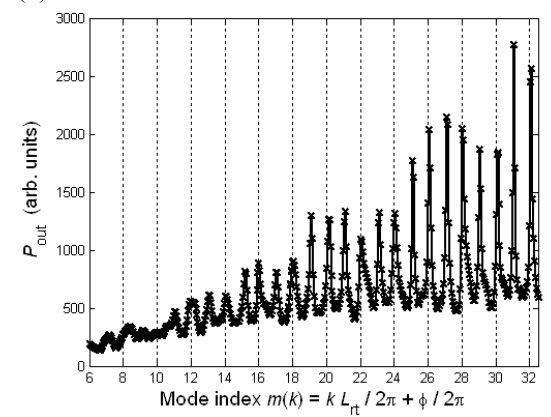

(c)

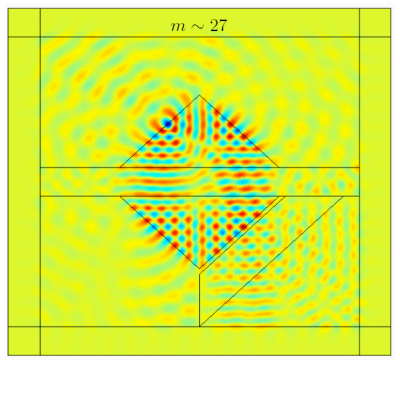

Fig. 2 (a) The geometry used in the FEM simulations of the cavity modes. $\ell_{2} / \ell_{1}=0.2, n_{1}=1.59, n_{2}=1.43$ (typical values). Near the geometry edges perfectly matching layers (PML) absorb the field and prevent reflections. The dashed line indicates a typical optical path. (b) The output power $P_{\text {out }}$ in the adjacent polymer region (waveguide) calculated for each $k$ value with the excitation source at point A, see Fig. 2(a). The plane-wave model predicts resonances for integer values of $m$.

(c) Norm of the electric field at the resonance at $m=27.1355$.

\section{References}

[1] E. Verpoorte, "Chip vision-optics for microchips", Lab. Chip 3, 42N-52N (2003).

[2] Y. Cheng, K. Sugioka, and K. Midorikawa, "Microfluidic laser embedded in glass by three-dimensional femtosecond laser microprocessing", Opt. Lett. 29, 2007-2009 (2004).

[3] M. Gersborg-Hansen, S. Balslev, N. A. Mortensen, and A. Kristensen, “A coupled cavity micro-fluidic dye ring laser", Microelectron. Eng. 78-79, 185-189 (2005). Presented at Micro and Nano Engineering 2004, September 19-22, 2004, Rotterdam, the Netherlands.

[4] J. C. Galas, J. Torres, M. Belotti, Q. Kou, and Y. Chen, "Microfluidic tunable dye laser with integrated mixer and ring resonator", Appl. Phys. Lett. 86, $264101(2005)$

[5] M. Gersborg-Hansen, S. Balslev, and N. A. Mortensen, "Finite-element simulation of cavity modes in a micro-fluidic dye ring laser", J. Opt. A: Pure Appl. Opt. 8, 17-20 (2006). doi:10.1088/1464-4258/8/1/003

[6] O. G. Peterson, J. P. Webb, W. C. McColgin, and J. H. Eberly, “Organic dye laser threshold”, J. Appl. Phys., 42, 1917-1928 (1971).

[7] B. Bilenberg, T. Rasmussen, S. Balslev, and A. Kristensen, "Real-time tunability of chip-based light source enabled by micro-fluidic mixing", J. Appl. Phys., accepted for publication (2006)

[8] K. K. Tsia and A. W. Poon, "Dispersion-guided resonances in two-dimensional photonic-crystal-embedded microcavities", Opt. Express, 12, 5711-5722 (2004). 